\title{
TSH measurement is not an appropriate screening test for autonomous functioning thyroid nodules: a retrospective study of 368 patients
}

\author{
Rayan Chami ${ }^{1}$, Rodrigo Moreno-Reyes ${ }^{2}$ and Bernard Corvilain ${ }^{1}$ \\ Departments of ${ }^{1}$ Endocrinology and ${ }^{2}$ Nuclear Medicine, Hôpital Erasme, Université Libre de Bruxelles, \\ route de Lennik 808, 1070 Brussels, Belgium
}

\author{
Correspondence \\ should be addressed \\ to B Corvilain \\ Email \\ bcorvila@ulb.ac.be
}

\begin{abstract}
Objective: Based on the assumption that normal TSH concentration rules out the presence of autonomous functioning thyroid nodules (AFTNs), clinical guidelines on the management of thyroid nodules only recommend a thyroid scan if TSH concentration is subnormal. However, the proportion of AFTN presenting with a normal TSH is unknown. Our objective is therefore to determine the proportion of AFTNs with a normal TSH level to ascertain whether a normal TSH really rules out an AFTN.
\end{abstract}

Design: Retrospective study on 368 patients with an AFTN.

Methods: Thyroid scans with a diagnosis of AFTN were reviewed retrospectively by one of us (R Moreno-Reyes), blinded to the clinical data. The diagnosis of solitary AFTN was confirmed in 368 patients. Among them, we selected 217 patients based on the absence of another thyroid nodule $>10 \mathrm{~mm}$, the absence of medical conditions able to interfere with thyroid function, and the completeness of the data.

Results: The proportion of AFTNs with normal TSH was $49 \%$. This proportion increased to $71 \%$ in patients for whom thyroid scan was performed in the workup of a thyroid nodule.

Conclusions: Our data suggest that serum TSH is not an effective screening tool to diagnose AFTNs. Using 'TSH-only' screening, as recommended by the majority of guidelines, the diagnosis of AFTN would have been missed in $71 \%$ of our patients in the workup of a thyroid nodule. Thyroid scan remains the gold standard for detecting AFTN and should be considered before performing fine-needle aspiration cytology (FNAC), as the reliability of FNAC in an unsuspected AFTN remains unclear.

\section{Introduction}

Management of thyroid nodules is a very common problem in adults (1). Thyroid scan is the only technique that permits evaluation of the functional characteristics of a nodule. The vast majority of nodules are hypofunctioning but a minority are hyperfunctioning, autonomously functioning thyroid nodules (AFTNs). AFTNs account for $5-10 \%$ of palpable nodules $(2,3)$. Thyroid scan is now rarely used in the management of thyroid nodules based on the assumption that thyroid-stimulating hormone (TSH) levels are always subnormal in the presence of an
AFTN. Several guidelines on thyroid nodule management have been published recently, among them are those by the American Association of Clinical Endocrinologists (AACE) in 2006 (4), the British Thyroid Association (BTA) in 2007 (5), the Latin American Thyroid Association in 2009 (6), the American Thyroid Association (ATA) in 2009 (7), joint guidelines (AAE) between three large societies, AACE, Associazione Medici Endocrinologi (AME), and the European Thyroid Association (ETA) published in 2010 (8) and the French Society of Endocrinology (SFE) in 2011 (9).
(C) 2014 European Society of Endocrinology Printed in Great Britain
Published by Bioscientifica Ltd. 
There is a general agreement between all the guidelines that a thyroid scan should be performed in the presence of subnormal TSH, but which patients, if any, with a thyroid nodule and a normal TSH deserve a thyroid scan remains an area of disagreement (10). AACE, BTA, ATA, and SFE guidelines recommend thyroid scan only when the level of TSH is subnormal or 'close to the lower limit of normal', but only AAE recommends considering thyroid scan in iodine-deficient areas even if the TSH level is in the normal range, particularly in the presence of a multinodular goiter. However, this assertion comes from small clinical studies (11) or expert opinions (12). All groups agree that AFTNs with a low TSH level do not necessitate FNAC, based on the very low risk of cancer in a hyperfunctioning thyroid nodule. The extension of this statement to AFTN with a normal TSH level is an area of disagreement but is proposed by some authors (10). In addition, FNAC of AFTNs is associated with a risk of equivocal results (follicular neoplasm) (13). Therefore, in the absence of a thyroid scan in the workup of a patient with a thyroid nodule and a normal TSH level, there is a risk of proposing FNAC in an unsuspected AFTN. However, the proportion of patients with an AFTN presenting with a normal TSH level is unknown. Historical series suggested that thyrotoxicosis was rare below a diameter of $2.5 \mathrm{~cm}$ and that the percentage of toxicity reaches only 30-40\% between 3 and $4.5 \mathrm{~cm}$ $(14,15)$. Since in our institution thyroid scan is still systematically performed in the workup of thyroid nodule and hyperthyroidism, we undertook a retrospective study aiming to analyze the relationship between nodule size and thyroid function and thus evaluate the proportion of AFTNs with a normal TSH level.

\section{Subjects and methods}

\section{Subjects}

Between 1993 and 2012, 11192 thyroid scans were performed in adult patients in our department of nuclear medicine. Among them, we found 466 patients with an output describing a solitary AFTN. All the thyroid scans were reviewed by one of us ( $\mathrm{R}$ Moreno-Reyes) blinded to the clinical data. The study flow diagram is presented in Fig. 1 . We included only patients with a certain AFTN diagnosed based on the thyroid scan using ${ }^{99 \mathrm{~m}} \mathrm{TcO} 4^{-}$. Ninety-eight patients were therefore excluded because of the presence of cystic AFTN or because an AFTN was possible but questionable on the scintigraphy. The diagnosis of a solitary AFTN was made by scintigraphy in 368 patients (Group I). The criterion for scintigraphic diagnosis of AFTN was the presence of an area of

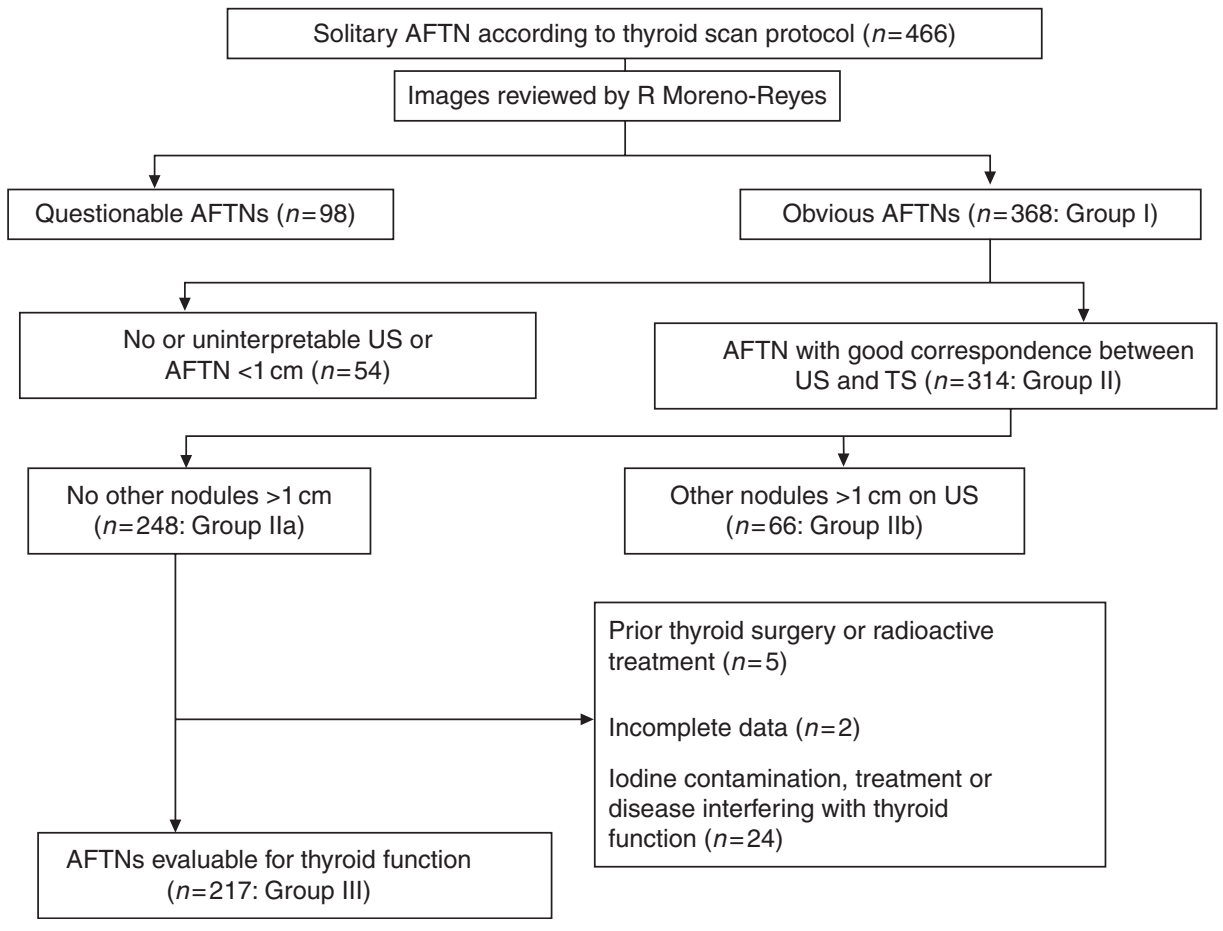

Figure 1

Study flow diagram of the selection of patients. AFTN, autonomous functioning thyroid nodule; US, ultrasound; TS, thyroid scan. 
increased radionuclide intake in comparison with remaining extranodular parenchyma. Among these patients (Group I), thyroid ultrasound (US) was not available for 24 patients and uninterpretable for 23 patients. Seven patients were excluded because their AFTN was $<10 \mathrm{~mm}$ on US. These 54 patients were excluded from subsequent analysis. A good correspondence between thyroid scan and US was observed in 314 patients (Group II). Patients without another nodule $>1 \mathrm{~cm}$ described on US were defined here as having a solitary AFTN and classified as Group IIa (248 patients) and those with another nodule $>1 \mathrm{~cm}$ as Group IIb (66 patients). The size of the nodule was estimated by US (main diameter and volume). Nodule volume in $\mathrm{ml}$ was calculated according to the following formula (height $\times$ width $\times$ depth expressed in $\mathrm{cm}) \times 0.524$. For the study of the relationship between the size of the nodule and thyroid function, we secondarily excluded 31 patients with incomplete data (no evaluation of thyroid function), with a history of iodide contamination (contrast agent $<3$ months, treatment by amiodarone $<12$ months), treatment by drugs interfering with thyroid function (e.g. thyroid hormones, corticoids and lithium for $<3$ months), treatment by anti-thyroid drugs $(<6$ months), and active disease that may interfere with thyroid function. The relationship between nodule size and thyroid function was determined when thyroid scans, US, and thyroid test results, from within a 6-month window, were all available in the patient's file. Thus, after these exclusions we obtained 217 evaluable patients (Group III). Among them, calculation of AFTN volume was possible in 176 patients.

\section{Assay}

The normal reference intervals for TSH remained unchanged at between 0.4 and $4 \mu \mathrm{U} / \mathrm{ml}$ over the period of the study. From 1993 to 06/1998, TSH was measured using a Chiren Diagnostics ACS:180 Plus automated chemiluminescence immunoassay analyzer (Ciba Corning
Diagnostics Corp., Medfield, MA, USA); from 07/1998 until now by electrochemiluminescence, initially to $10 / 2002$ using an Elecsys (Roche-Boehringer); and from 11/2002 until now using a module E170 (Roche Diagnostics).

\section{Analysis of the clinical data}

Each patient undergoing thyroid scan was examined by the physician working in the department of Nuclear Medicine who summarizes the clinical data. We used this summary to identify the reason for performing the thyroid scan. Other clinical data were found in the medical file of the patient and used to determine the first time point at which all the data were available. Therefore, in some patients, age at analysis may differ from age at diagnosis.

\section{Statistical analysis}

Statistical analyses were performed using Prism 5 (GraphPad Software, San Diego, CA, USA). Data were expressed as means \pm s.E.M. Two-tailed unpaired $t$-test was used to compare groups for age or AFTN size and Mann-Whitney $U$ test or Kruskall-Wallis test were used for comparison of TSH values. Comparison of proportions was made using the $\chi^{2}$-test. The level of significance was set at $P<0.05$.

\section{Ethical approval}

This study was approved by the ethics board at the Hôpital Erasme (P2011/063).

\section{Results}

\section{Age and sex distribution}

Among the 368 patients with AFTN, the female-to-male ratio was 2.9 (Table 1 ). We had no reliable data on age at

Table 1 Characteristics of patients of Group I with AFTNs according to the circumstances of diagnosis ${ }^{\mathrm{a}}$.

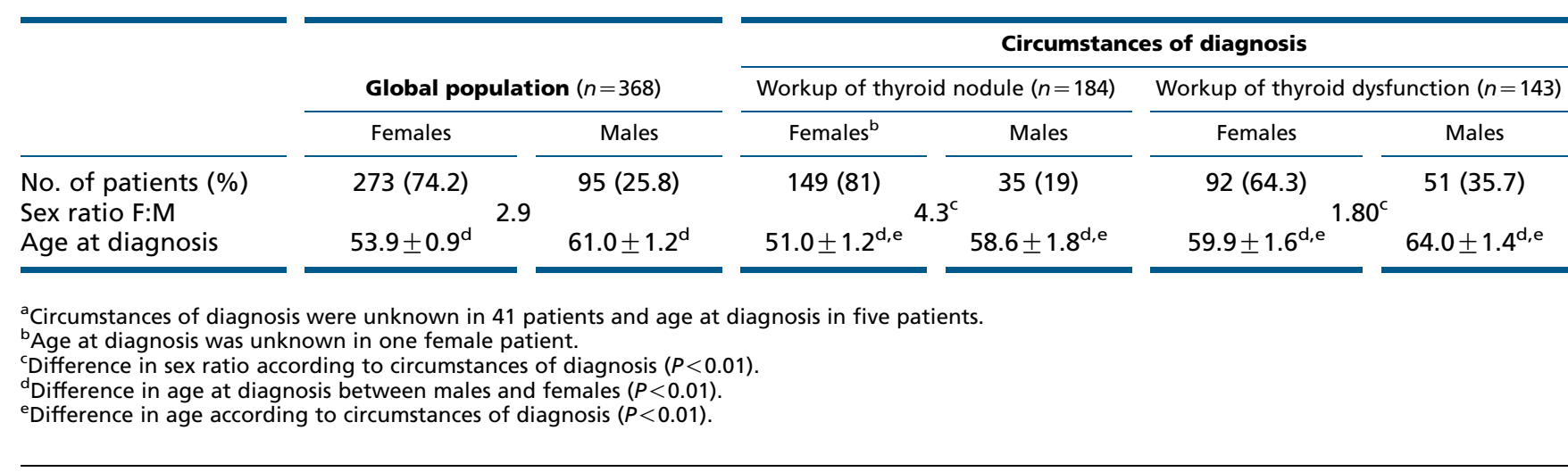




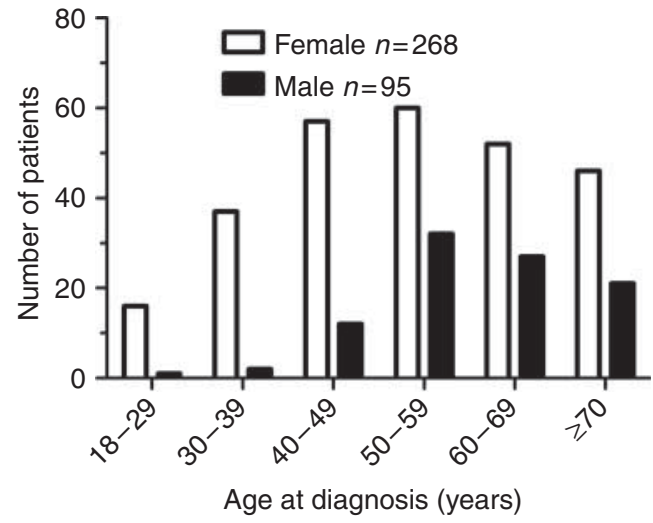

Figure 2

Age and sex distribution of patients with AFTN (Group I). Age at diagnosis was unknown in five patients. $\chi^{2}$-test for trend $P<0.01$.

diagnosis for five patients. Female patients were significantly younger at diagnosis than men. Male patients were rare below 40 years and the sex ratio F:M decreased abruptly with age from $\sim 18$ below 40 years to $\sim 2.0$ above 50 years $(P<0.01)$ (Fig. 2$)$.

\section{Circumstances of diagnosis}

No reliable data on the circumstances of diagnosis were available for 41 patients (32 females and nine males). Data were therefore analysed for 327 patients. AFTN was more frequently diagnosed in the workup of thyroid nodules in females and in the workup of thyroid dysfunction in males $(P<0.01)$ (Table 1). Patients with AFTN discovered in the workup of a thyroid nodule were significantly younger than those whose AFTN was discovered in the workup of thyroid dysfunction $(P<0.01$ in females and males).

\section{AFTN size and distribution}

AFTN was located in the isthmus in 15 patients, but more frequently in the right lobe (221 patients) than in the left lobe (132 patients) $(P<0.01)$. For the calculation of the size of AFTNs, we excluded those $<10 \mathrm{~mm}$ and those for which we had no reliable US data. Data on the mean size of AFTNs at the time of analysis were therefore available for 314 patients. The mean size was $28.0 \pm 0.7 \mathrm{~mm}$, with no differences between males $(29.5 \pm 1.2 \mathrm{~mm})$ and females $(27.5 \pm 0.8 \mathrm{~mm})$.

\section{Thyroid function}

We excluded all patients with the conditions that may interfere with thyroid function or with other nodules
$>1 \mathrm{~cm}$. The analysis of the relationship between AFTN size and thyroid function was carried out only in Group III when all reliable data were available for the first time. This explains why age at analysis $(53.9 \pm 1.0)$ differs slightly from age at diagnosis $(53.0 \pm 1.0)$. In Group III (Table 2), TSH levels $<0.4 \mu \mathrm{U} / \mathrm{ml}$ were observed in 110 of 217 patients (50.7\%): 77 females and 33 males (sex ratio 2.33), and $\geq 0.4 \mu \mathrm{U} / \mathrm{ml}$ in 107 patients (49.3\%): 83 females and 24 males (sex ratio 3.46). As expected, the main diameter and the volume of the nodule were greater in the subgroup with a TSH level $<0.4 \mu \mathrm{U} / \mathrm{ml}$. To address more precisely the question of the sensitivity of a subnormal TSH level in the detection of an AFTN during the workup of a thyroid nodule, in Fig. 3, we compare results obtained for the whole population (Group III $(n=217)$ ) and results obtained for patients for whom the diagnosis of AFTN was made during the workup of a thyroid nodule $(n=122)$. In the whole population, normal TSH was observed in $49 \%$ of AFTNs. This proportion increased to $71 \%$ in the subpopulation where AFTN was discovered in the workup of a thyroid nodule (Fig. 3a). The relationship between the size of the nodule (main diameter or volume) and the persistence of a normal TSH level in the whole population and in the subpopulation where AFTN was discovered in the workup of a thyroid nodule is shown in Fig. $3 \mathrm{~b}$ and c. We observed a decrease in the proportion of AFTNs with a normal TSH level with increase in size of the nodule, but in the workup of a thyroid nodule, the majority of patients with AFTNs maintained a TSH $\geq 0.4 \mu \mathrm{U} / \mathrm{ml}$ for a maximal diameter up to $40 \mathrm{~mm}$ or a volume up to $10 \mathrm{ml}$. In the

Table 2 Characteristics of AFTNs in patients of Group III ( $n=217$ ) according to TSH level ( $<$ or $\geq 0.4 \mu \mathrm{U} / \mathrm{ml}$ ). Except for $\mathrm{TSH}$, values are means \pm s.E.M.

\begin{tabular}{|c|c|c|}
\hline & TSH $<0.4 \mu \mathrm{U} / \mathrm{ml}$ & TSH $\geq 0.4 \mu \mathrm{U} / \mathrm{ml}$ \\
\hline No. of patients (\%) & $110(50.7)$ & $107(49.3)$ \\
\hline Sex ratio F:M & $2.3(77: 33)$ & $3.5(83: 24)$ \\
\hline Age at analysis & $54.4 \pm 1.4$ & $53.3 \pm 1.4$ \\
\hline $\begin{array}{l}\text { Median }(\mathrm{P} 25-\mathrm{P} 75) \mathrm{TSH} \\
\text { value }(\mu \mathrm{U} / \mathrm{ml})\end{array}$ & $0.04(0.04-0.13)$ & $0.91(0.70-1.34)$ \\
\hline $\begin{array}{l}\text { Main diameter of the } \\
\text { nodule }(\mathrm{mm})\end{array}$ & $33.03 \pm 1.15$ & $24.66 \pm 1.10^{a}$ \\
\hline Volume of the nodule $(\mathrm{ml})^{\mathrm{b}}$ & $11.32 \pm 1.38$ & $5.31 \pm 0.70^{a}$ \\
\hline $\begin{array}{l}\text { Circumstances of diagnosis: } \\
\text { thyroid dysfunction- } \\
\text { nodule-unknown }\end{array}$ & 63/35/12 & $11^{c} / 87 / 9^{d}$ \\
\hline
\end{tabular}

${ }^{a}$ Mean was statistically different from subjects with $\mathrm{TSH}<0.4 \mu \mathrm{U} / \mathrm{m}$ $(P<0.01)$.

${ }^{\mathrm{b}}$ Three-dimensional measurement was available in 176 patients.

${ }^{\mathrm{c}}$ For 11 patients we observed a spontaneous normalization of the TSH level at the time of analysis.

${ }^{\mathrm{d}}$ Proportions were statistically different from subjects with TSH $<0.4 \mu \mathrm{U} / \mathrm{ml}$ $(P<0.01)$. 
(a)

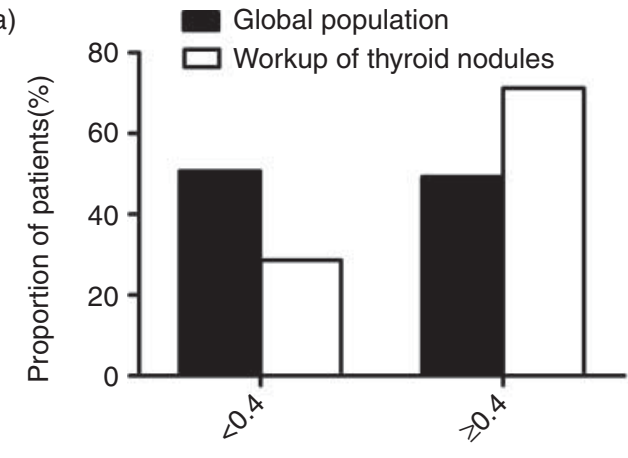

TSH value $(\mu \mathrm{U} / \mathrm{ml})$
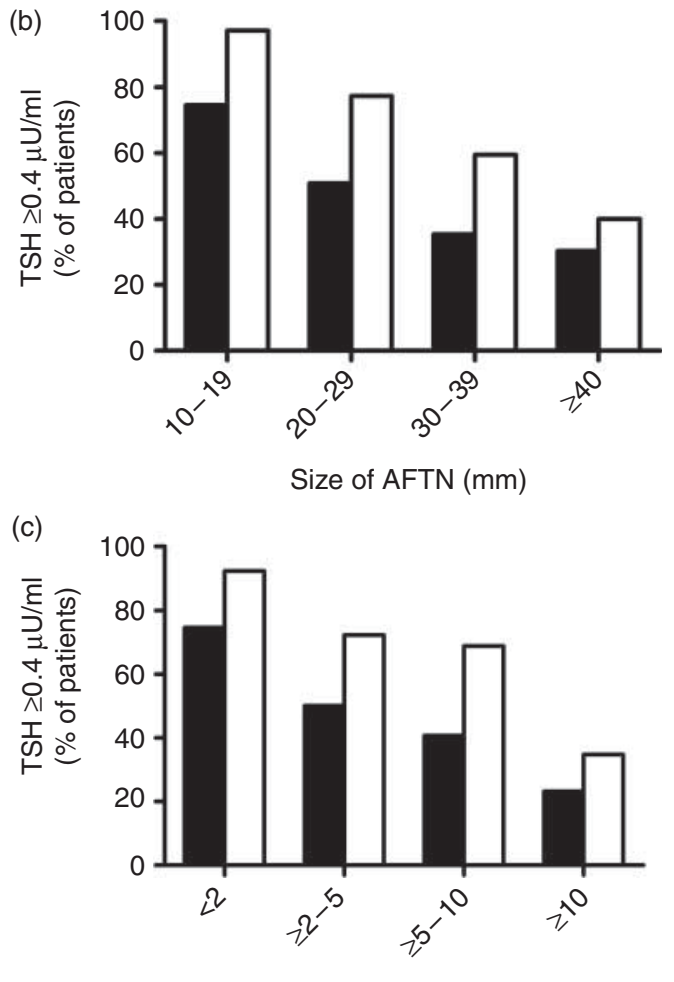

Volume of AFTN (ml)

\section{Figure 3}

Patients from Group III. (a) Proportion of patients with an AFTN and a normal TSH level. ( $b$ and $c$ ) Proportion of patients with a normal TSH level according to the size of the nodule (main diameter (b) or volume (c)). Black bars, global population; white bars, subpopulation in which the AFTN was discovered in the workup of a thyroid nodule.

global population of AFTN, the median serum TSH was 0.38 and $0.80 \mu \mathrm{U} / \mathrm{ml}$ when AFTN was discovered in the workup of thyroid nodule. As shown in Table 3, median values decrease with the size of the nodule $(P<0.01)$, but it was not possible do determine a threshold above which an AFTN was unlikely. Whatever the size of the nodule is the 75th and 90th percentiles remain clearly in the normal range, particularly when AFTN was discovered in the workup of a thyroid nodule. This confirms that even a 'low normal' TSH value does not permit diagnosis of AFTN.

\section{Discussion}

The present study is a retrospective study carried out using clinical data of 368 patients with an AFTN. Our data indicate that serum TSH measurement is not an effective screening test to diagnose an AFTN because $71 \%$ of the patients included in our study for the assessment of a thyroid nodule had a normal TSH value.

As has been observed already in previous series, a higher prevalence of AFTN is observed in women, but less so than previously reported $(14,15,16)$. However, our study allowed collection of new and interesting data: the age at which a nodule comes to clinical attention is lower in females than in males and the sex ratio F:M progressively decreases with age from 18 below 40 years to $\sim 2$ above 50 years, suggesting a role of estrogens in the occurrence and growth of hot nodules, as has been suggested more generally for thyroid tumors (17). Another interesting finding is the fact that, even if the size of the nodule is similar in males and females, most AFTNs were diagnosed in the workup of thyroid nodule in females and in the workup of thyroid dysfunction in males. Age at diagnosis was higher when an AFTN was diagnosed in the workup of thyroid dysfunction. This could be a recruitment bias due to the more frequent use of routine blood analysis in elderly patients and therefore the diagnosis of asymptomatic hyperthyroidism.

In the second part of the study, we analysed the relationship between the size of the autonomous nodules, evaluated by US, and thyroid function in 217 patients with a solitary AFTN. If we considered this population as a whole, $49 \%$ of those patients had a TSH level $\geq 0.4 \mu \mathrm{U} / \mathrm{ml}$. If we analysed only patients for whom the scan had been performed in the workup of a thyroid nodule, this proportion increases to $71 \%$. This proportion was not related to gender or age, but was inversely related to the size of the nodule. However, some patients are hyperthyroid for a nodule with a diameter $<2 \mathrm{~cm}$ and some are not for nodule with a diameter $>5 \mathrm{~cm}$. Gain-of-function mutations of the TSHR or GNAS are the main cause of AFTN. More than 40 TSHR mutations have been reported, but the correlation between the in vitro activity of a mutated receptor and the clinical phenotype is weak (18). Therefore, the heterogeneity in clinical behaviour of AFTN is probably not caused by differences in causal TSHR 
Table 3 Parameters of distribution of TSH values in patients from Group III according to the size of the nodule (main diameter or volume) and the circumstances of diagnosis ${ }^{a}$.

\begin{tabular}{|c|c|c|c|c|c|c|c|c|}
\hline & \multicolumn{8}{|c|}{ TSH value $(\mu \mathrm{U} / \mathrm{ml})$} \\
\hline & \multicolumn{4}{|c|}{ Global population } & \multicolumn{4}{|c|}{ Work up of thyroid nodule } \\
\hline & P25 & P50 & P75 & P90 & P25 & P50 & P75 & P90 \\
\hline \multicolumn{9}{|c|}{ Size of the nodule $(\mathrm{mm})$} \\
\hline $10-19$ & 0.38 & 0.80 & 1.14 & 1.60 & 0.76 & 0.96 & 1.35 & 1.80 \\
\hline $20-29$ & 0.04 & 0.46 & 0.91 & 1.42 & 0.46 & 0.90 & 1.20 & 2.04 \\
\hline $30-39$ & 0.04 & 0.11 & 0.65 & 1.30 & 0.04 & 0.55 & 0.92 & 1.44 \\
\hline$\geq 40$ & 0.04 & 0.05 & 0.67 & 2.08 & 0.04 & 0.18 & 1.57 & 3.24 \\
\hline \multicolumn{9}{|c|}{ Size of the nodule (ml) } \\
\hline$<2$ & 0.38 & 0.80 & 1.18 & 1.64 & 0.78 & 1.05 & 1.35 & 1.83 \\
\hline$\geq 2-5$ & 0.05 & 0.41 & 0.90 & 1.27 & 0.28 & 0.84 & 1.13 & 2.11 \\
\hline$\geq 5-10$ & 0.04 & 0.13 & 0.71 & 1.40 & 0.12 & 0.62 & 0.93 & 1.50 \\
\hline$\geq 10$ & 0.04 & 0.04 & 0.29 & 1.20 & 0.04 & 0.12 & 0.53 & 2.03 \\
\hline
\end{tabular}

${ }^{\text {a Percentile }} 25$ (P25), Percentile 50 (P50), Percentile 75 (P75), Percentile 90 (P90).

mutations. This heterogeneity may instead reflect the heterogeneity of cellular density from one nodule to another due to various decreases in colloid space, the difficulty of estimating the actual weight of the active nodule (19) or the presence of an impaired iodide organification as observed in $60 \%$ of AFTNs (20). Similar to several other countries, Belgium is an area with mild iodine deficiency $(21,22)$, and the goitrogenic role of pregnancy is observed only in iodine-deficient areas (23). Therefore, we cannot claim that our observation is valid for patients from areas with optimal iodine intake. However, the only study that compared thyroid function in patients with AFTN from iodine-deficient or -sufficient areas reported no differences in the proportion of patients with hyperthyroidism (14). On the basis of 'TSH-only' screening, $71 \%$ of the patients included in our study for the assessment of a thyroid nodule would have undergone a FNAC within an AFTN with undetermined proportion of false-positive suspicious results. Even if the benign nature of the nodule is confirmed, follow-up will be different for an AFTN because it will mainly consist of detection and adequate treatment of thyroid dysfunction. To evaluate the most appropriate strategy, the risk of obtaining an equivocal result in FNAC of an AFTN should be quantified in a prospective study as well as the risk of cancer in an AFTN patient with a low or a normal TSH level.

\section{Strengths and limitations of the study}

Our study is one of the largest studies on AFTNs with reliable clinical data, sensitive TSH measurement, and using US to evaluate more accurately the size of the nodule and identify patients with multinodular disease. One limitation of our study is the use of ${ }^{99} \mathrm{mcO}^{-}$to detect AFTN. Some nodules may appear 'hot' on ${ }^{99 \mathrm{~m}} \mathrm{TcO} 44^{-}$and cold on 123-I. This discordance is observed in only $5 \%$ of patients and therefore could not explain our results (24). In the same way, thyroid hormone suppression tests were not done; therefore, we cannot exclude the possibility that some nodules with increased ${ }^{99 \mathrm{~m}}$ technetium uptake are not autonomously functioning. The fact that our study is a retrospective study is an important limitation because only AFTNs that came to clinical attention were selected. However, the generalized use of thyroid scan in our institution for patients with thyroid nodules as well as for patients with hyperthyroidism limits the risk of systematic bias.

\section{Conclusion}

TSH measurement is not an effective test to detect the presence of an AFTN in the workup of a thyroid nodule. Thyroid scan still has a role in the workup of a thyroid nodule, because it remains the only technique that permits the diagnosis of an AFTN, a diagnosis accounting for $5-10 \%$ of palpable nodules, which do probably not require further investigation.

Declaration of interest

The authors declare that there is no conflict of interest that could be perceived as prejudicing the impartiality of the research reported.

Funding

This research did not receive any specific grant from any funding agency in the public, commercial or not-for-profit sector. 


\section{Author contribution statement}

$\mathrm{R}$ Chami made primary contributions to data collection and analysis, interpretation of results, and writing the manuscript. $\mathrm{R}$ Moreno-Reyes and B Corvilain contributed to the study concept and design. All authors contributed to the interpretation of results, all revised the manuscript critically for important intellectual content and all approved the final manuscript.

\section{Acknowledgements}

We thank Global Science Editing Ltd for their help preparing the manuscript.

\section{References}

1 Mazzaferri EL. Management of a solitary thyroid nodule. New England Journal of Medicine 1993328 553-559. (doi:10.1056/ NEJM199302253280807)

2 Hegedüs L, Bonnema SJ \& Bennedbaek FN. Management of simple nodular goiter: current status and future perspectives. Endocrine Reviews 200324 102-132. (doi:10.1210/er.2002-0016)

3 Hamburger JI. The autonomously functioning thyroid nodule: Goetsch's disease. Endocrine Reviews 19878 439-447. (doi:10.1210/ edrv-8-4-439)

4 Gharib H, Papini E, Valcavi R, Baskin HJ, Crescenzi A, Dottorini ME, Duick DS, Guglielmi R, Hamilton CR Jr, Zeiger MA et al. American Association of Clinical Endocrinologists and Associazione Medici Endocrinologi medical guidelines for clinical practice for the diagnosis and management of thyroid nodules. Endocrine Practice 200612 63-102. (doi:10.4158/EP.12.2.223)

5 Guidelines for the management of thyroid cancer. British Thyroid Association http://www.british-thyroid-association.org/news/Docs/ Thyroid_cancer_guidelines_2007.pdf.

6 Camargo R, Corigliano S, Friguglietti C, Gauna A, Harach R, Munizaga F, Niepomniszcze H, Pitoia F, Pretell E, Vaisman M et al. Latin American thyroid society recommendations for the management of thyroid nodules. Arquivos Brasileiros de Endocrinologia e Metabologia 2009 53 1167-1175. (doi:10.1590/S0004-27302009000900014)

7 American Thyroid Association (ATA) Guidelines Taskforce on Thyroid Nodules and Differentiated Thyroid Cancer, Cooper DS, Doherty GM, Haugen BR, Kloos RT, Lee SL, Mandel SJ, Mazzaferri EL, McIver B, Pacini F et al. Revised American Thyroid Association management guidelines for patients with thyroid nodules and differentiated thyroid cancer. Thyroid 200919 1167-1214. (doi:10.1089/thy.2009.0110)

8 Gharib H, Papini E, Paschke R, Duick DS, Valcavi R, Hegedüs L, Vitti P \& AACE/AME/ETA Task Force on Thyroid Nodules . American Association of Clinical Endocrinologists, Associazione Medici Endocrinologi, and European Thyroid Association Medical Guidelines for Clinical Practice for the Diagnosis and Management of Thyroid Nodules. Endocrine Practice 201016 (Suppl 1) 1-43. (doi:10.4158/10024.GL)

9 Wémeau JL, Sadoul JL, d'Herbomez M, Monpeyssen H, Tramalloni J, Leteurtre E, Borson-Chazot F, Caron P, Carnaille B, Léger J et al. Guidelines of the French Society of Endocrinology for the management of thyroid nodules. Annales d'Endocrinologie 201172 251-281. (doi:10.1016/j.ando.2011.05.003)

10 Paschke R, Hegedüs L, Alexander E, Valcavi R, Papini E \& Gharib H. Thyroid nodule guidelines: agreement, disagreement and need for future research. Nature Reviews. Endocrinology 20117 354-614. (doi:10.1038/nrendo.2011.1)

11 McHenry CR, Slusarczyk SJ, Askari AT, Lange RL, Smith CM, Nekl K \& Murphy TA. Refined use of scintigraphy in the evaluation of nodular thyroid disease. Surgery $1998 \mathbf{1 2 4}$ 656-661. (doi:10.1067/msy.1998. 91222)

12 Meier DA \& Kaplan MM. Radioiodine uptake and thyroid scintiscanning. Endocrinology and Metabolism Clinics of North America 200130 291-313. (doi:10.1016/S0889-8529(05)70188-2)

13 Burch HB, Shakir F, Fitzsimmons TR, Jaques DP \& Shriver CD. Diagnosis and management of the autonomously functioning thyroid nodule: the Walter Reed Army Medical Center experience, 1975-1996. Thyroid 199810 871-880. (doi:10.1089/thy.1998.8.871)

14 Belfiore A, Sava L, Runello F, Tomaselli L \& Vigneri R. Solitary autonomously functioning thyroid nodules and iodine deficiency. Journal of Clinical Endocrinology and Metabolism 198356 283-287. (doi:10.1210/jcem-56-2-283)

15 Hamburger JI. Evolution of toxicity in solitary nontoxic autonomously functioning thyroid nodules. Journal of Clinical Endocrinology and Metabolism 198050 1089-1093. (doi:10.1210/jcem-50-6-1089)

16 Sandrock D, Olbricht T, Emrich D, Benker G \& Reinwein D. Long-term follow-up in patients with autonomous thyroid adenoma. Acta Endocrinologica $1993 \mathbf{1 2 8}$ 51-55.

17 Manole D, Schildknecht B, Gosnell B, Adams E \& Derwahl M. Estrogen promotes growth of human thyroid tumor cells by different molecular mechanisms. Journal of Clinical Endocrinology and Metabolism 200186 1072-1077. (doi:10.1210/jcem.86.3.7283)

18 Lueblinghoff J, Eszlinger M, Jaeschke H, Mueller S, Bircan R, Gozu H, Sancak S, Akalin S \& Paschke R. Shared sporadic and somatic thyrotropin receptor mutations display more active in vitro activities than familial thyrotropin receptor mutations. Thyroid 201121 221-229. (doi:10.1089/thy.2010.0312)

19 Corvilain B, Van Sande J, Dumont JE \& Vassart G. Somatic and germline mutations of the TSH receptor and thyroid diseases. Clinical Endocrinology 200155 143-158. (doi:10.1046/j.1365-2265.2001.01365.x-i2)

20 Moreno-Reyes R, Tang BN, Seret A, Goldman S, Daumerie C \& Corvilain B. Impaired iodide organification in autonomous thyroid nodules. Journal of Clinical Endocrinology and Metabolism 200792 4719-4724. (doi:10.1210/jc.2007-0833)

21 Moreno-Reyes R, Carpentier YA, Macours P, Gulbis B, Corvilain B, Glinoer D \& Goldman S. Seasons but not ethnicity influence urinary iodine concentrations in Belgian adults. European Journal of Nutrition 201150 285-290. (doi:10.1007/s00394-010-0137-4)

22 Pearce EN, Andersson M \& Zimmermann MB. Global iodine nutrition where do we stand in 2013? Thyroid 201323 523-528. (doi:10.1089/ thy.2013.0128)

23 Knudsen N, Laurberg P, Perrild H, Bülow I, Ovesen L \& Jørgensen T. Risk factors for goiter and thyroid nodules. Thyroid 200212 879-888. (doi:10.1089/105072502761016502)

24 Reschini E, Ferrari C, Castellani M, Matheoud R, Paracchi A, Marotta G \& Gerundini $P$. The trapping-only nodules of the thyroid gland: prevalence study. Thyroid 200616 757-762. (doi:10.1089/thy.2006.16.757)
Received 7 December 2013

Revised version received 14 January 2014

Accepted 21 January 2014 